\title{
Minimization of Cogging Force in a Stationary Discontinuous Armature Linear Permanent Magnet Motor at the Outlet Edge
}

\author{
Yong-Jae Kim ${ }^{1}$ and Sang-Yong Jung ${ }^{2 *}$ \\ ${ }^{1}$ Dept. of Electrical Engineering, Chosun University, Gwangju 501-759, Korea \\ ${ }^{2}$ School of Information and Communication Engineering, Sungkyunkwan University, Suwon 440-746, Korea
}

(Received 16 June 2011, Received in final form 12 July 2011, Accepted 16 July2011)

\begin{abstract}
Generally, the discontinuous armature permanent magnet linear synchronous motor (PM-LSM) is composed by the stator block (accelerator, re-accelerator, and decelerator) and the free running section. However, the stationary discontinuous armature design involves the velocity variation of the mover during drive when the armature's non-installation part changes over to installation part as a result of the outlet edge of the armature. Therefore, we considered deforming the shape of the outlet edge at the armature and apply skew on the permanent magnet by displacing the two magnet segments of each pole. This paper presents the results of a threedimensional (3-D) numerical analysis with a finite element method (FEM) of the force exerted by the outlet edge.
\end{abstract}

Keywords : permanent magnet linear synchronous motor, discontinuous armature, outlet edge, attractive force, threedimensional numerical analysis, energy conversion

\section{Introduction}

Systems using permanent magnets with high-energy magnetic materials have been produced and distributed mainly through the factory automation field $[1,2]$. Particularly, linear motors have been developed as a mainstream in this field. Permanent magnet type linear synchronous motors (PM-LSMs) have been used as a driving source of transportation systems [3-6]. Generally, PMLSM arranges the stator on the overall transport path, increasing the initial cost of PM-LSM for long-distance transportation. In order to reduce this initial cost, application of discontinuous stator of PM-LSM to the transportation system has been carefully examined [7]. As this system arranges the stator (armature) discontinuously, the quantity of the stator is decreased dramatically. This system is structured by three stator blocks which are: the accelerator, re-accelerator and the decelerator. In this system, several stator blocks can be arranged at certain intervals within the overall running route. The space between the blocks without the stator is called the freewheeling section, and the mover in this section drives by

*Corresponding author: Tel: +82-31-299-4952

Fax: +82-31-290-5828, e-mail: syjung@ece.skku.ac.kr its own inertia. However, the stationary discontinuous armature PM-LSM has a problem that the force generated at each outlet edge which exists as a result of the discontinuous arrangement of the armature affects the drive of the mover [7]. Therefore, we considered deforming the shape of the outlet edge at the armature and apply skew on the permanent magnet by displacing the two magnet segments of each pole in order to reduce the force of the outlet edge.

This paper presents the results of 3-D numerical analysis by the FEM of the force exerted by the outlet edge as a result of the deforming the outlet edge at the armature and the permanent magnet on the mover.

\section{The Stationary Discontinuous Armature PM-LSM}

The appearance of the experimental device is shown in Fig. 1(a) and the armature arrangement is given schematically in Fig. 1(b). Several armature blocks can be arranged at certain intervals within the total length of $6500 \mathrm{~mm}$. The device has three stator parts: From left to right, they are referred to as the accelerator, the re-accelerator and the decelerator. The driving characteristics of the mover during re-acceleration when freewheeling changes over to 


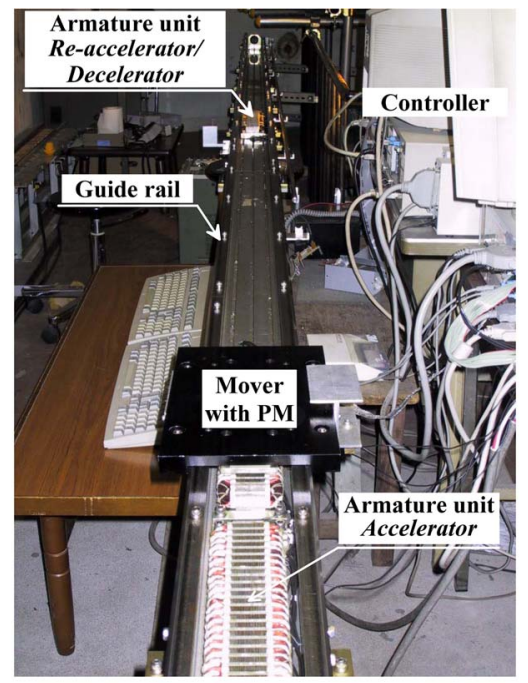

(a)

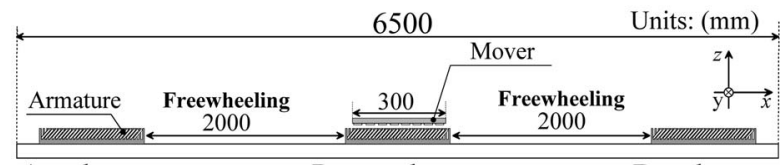

Accelerator Re-accelerator Decelerator

(b)

Fig. 1. (Color online) Experimental device: (a) Outline of experimental device and (b) Schematic representations of armature unit.

re-acceleration are shown in Fig. 2. As indicated by Fig. 2 , the velocity-position characteristics confirm that stable acceleration characteristics are obtained. However, the velocity increases at the entry interval (Position $0 \mathrm{~mm}$ is the point where the mover enters the armature) and decreases at the ejection interval (position $700 \mathrm{~mm}$ is the point where the mover begins to move beyond the armature). This may be attributed to the attractive force at the outlet edge which exists as a result of the discontinuous arrangement of the armature. This attractive force can

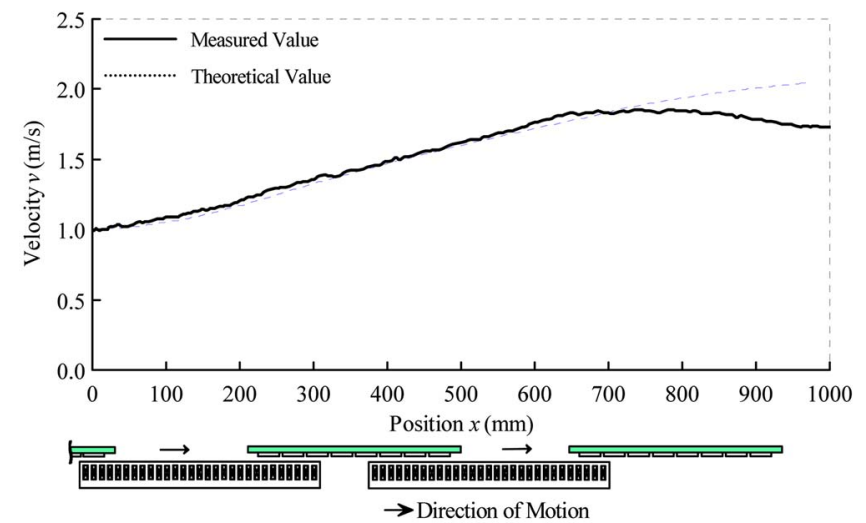

Fig. 2. (Color online) Re-acceleration characteristics. be divided into two different forces: i) the cogging force produced in the same direction as the PM-LSM's thrust force (the direction of a x-axis) between the permanent magnet and the armature's core and ii) the normal force produced in the direction of an air-gap (the direction of a z-axis) between the permanent magnet and the armature's core. The attractive force produced at the entry interval operates in the same direction as the mover and generated at the ejection interval operates in the opposite direction to the mover. Due to the effect of the force that operates at the each outlet edge, it has become a problem that the velocity of the mover is different from that of the velocity command during re-acceleration.

\section{Minimization Method of the Force Generated at the Outlet Edge}

\subsection{Basic model}

We examined the cogging force generated at each outlet edge by 3-D numerical analysis. The basic model used for the 3-D numerical analysis is shown in Fig. 3. The armature used for measurement has 17 slots and 4-pole permanent magnets which are arranged in the mover. The mover features an arrangement of neodymium-based rareearth magnets (NEOMAX-39SH) on a magnetic plate. The permanent magnets provide $\mathrm{BH}_{\max }=319 \mathrm{~kJ} / \mathrm{m}^{3}$ and the pole pitch is $33 \mathrm{~mm}$, and air-gap is $5 \mathrm{~mm}$ between the armature and the mover. Also, the pitch of the slot of the armature is $11 \mathrm{~mm}$. Moreover, we made a half model using the general-purpose electromagnetic field analysis software and performed 3-D numerical analysis using the FEM. The number of elements is 261337 , and the number of nodes is 137649 . The air region of the whole model (including an air-gap region) employs an automatic element generator which automatically adds mesh and generates elements every time the mover moves. The amount of movement per step is an interval of $1 \mathrm{~mm}$.

\subsection{Proposed models for reducing the cogging force at the outlet edge}

The basic model is arranged in the armature coil as a short-pitch winding, so the (A) and (B) slots of the basic model in Fig. 3 become a single layer. We have proposed and examined the method of adjusting the tooth lengths of the outlet edge of the armature and skew on the permanent magnet by displacing the two magnet segments of each pole to decrease the cogging force generated at the outlet edge. Through the examination of the characteristics of the outlet cogging force using the method of adjusting the tooth lengths of the outlet edge and the permanent magnet on the mover as proposed, we discovered 


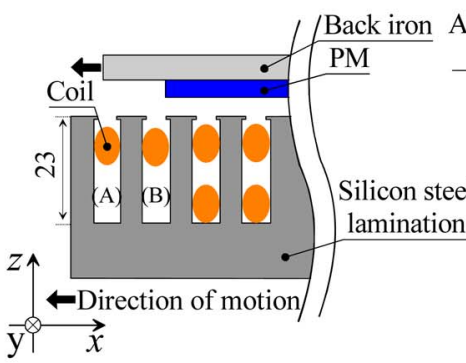

(a)

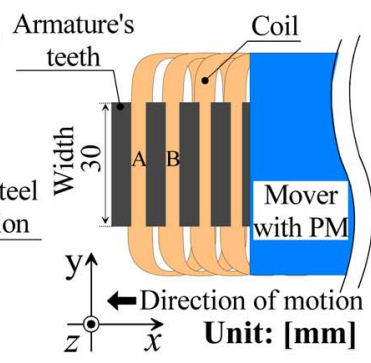

(b)

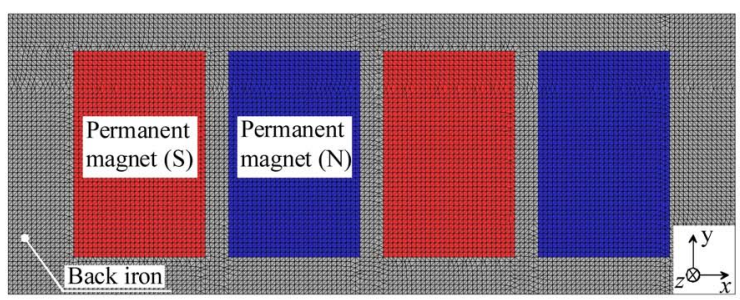

(c)

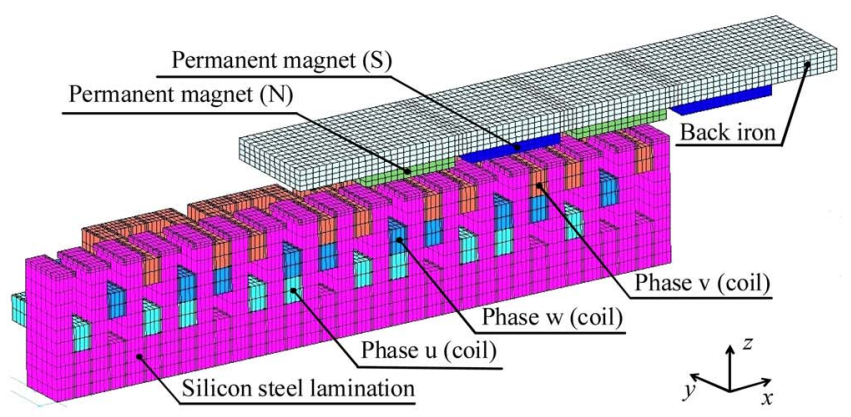

(d)

Fig. 3. (Color online) Basic model: (a) side view of the armature from the y-axis, (b) top view from the z-axis of the armature, (c) mover with permanent magnet, and (d) 3-D numerical analysis basic model.

that the outlet edge cogging force was decreased when the teeth of the outlet edge were which two-thirds the original length more than it did when the teeth were one-third the original length and mover with two permanent magnet segments/pole displaced by $27.3^{\circ}$ mech. In order to decrease the cogging force of the outlet edge further, we deformed the shape of the outlet edge of the armature side by dividing the $30 \mathrm{~mm}$ armature width of the single layer into 3 equal parts and cutting one-third of the armature width. The proposed model that deforms the shape of the outlet edge at the armature side to decrease the cogging force is shown in Fig. 4. We examined the cogging force at the outlet edge using the basic model and the 3 proposed models with adjusted the widths of the armature of each tooth. In this paper, only the shape of the outlet edge of the armature side at the ejection interval is changed. Then, we made each model a half model using the general-

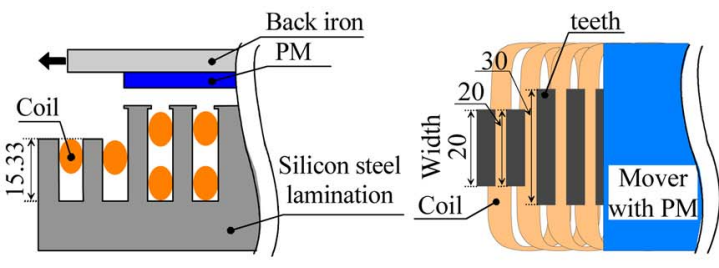

(a)
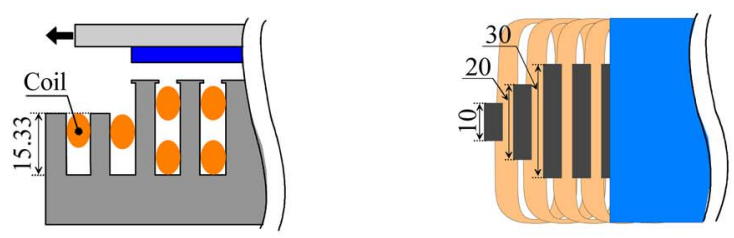

(b)
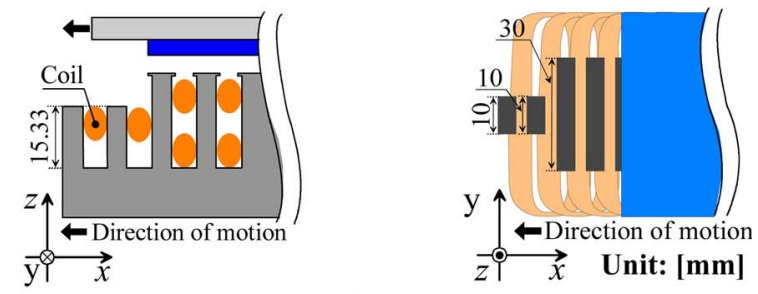

(c)

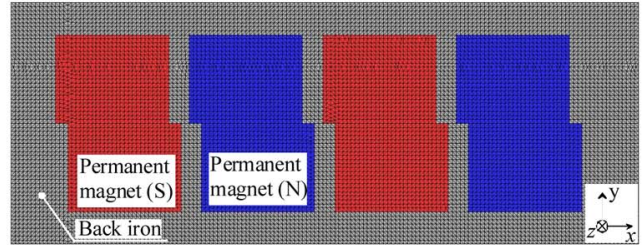

(d)

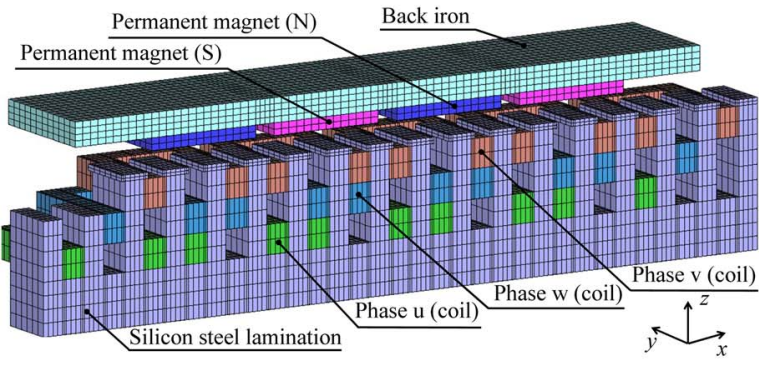

(e)

Fig. 4. (Color online) Proposed model: (a) The armature of proposed model \#1, (b) The armature of proposed model \#2, (c) The armature of proposed model \#3, (d) Mover with two permanent magnet segments/pole displaced by $27.3^{\circ}$ mech of the proposed model, and (e) 3-D numerical analysis proposed model.

purpose electromagnetic field analysis software and performed 3-D numerical analysis using the FEM on them.

\subsection{Three-dimensional numerical analysis results}

Fig. 5 shows the shape of the cogging force waveform 


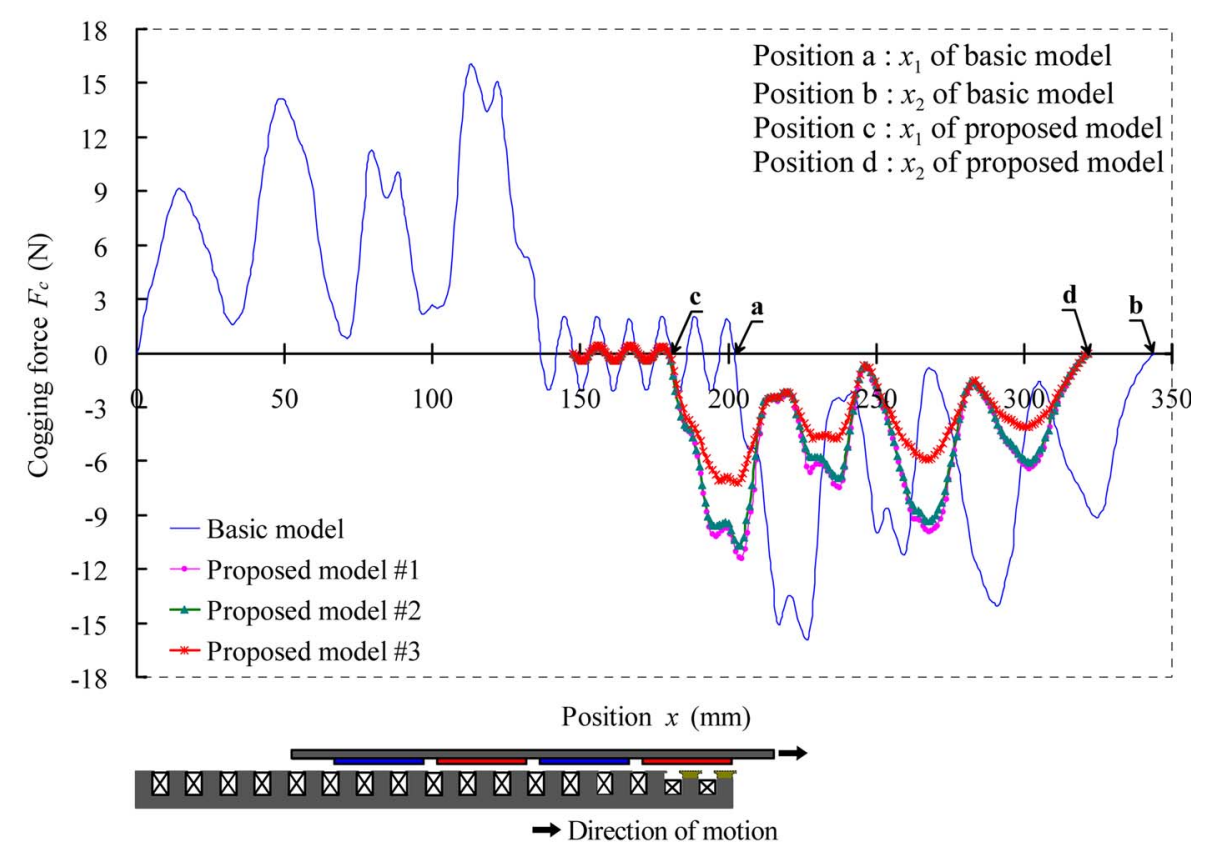

(a)

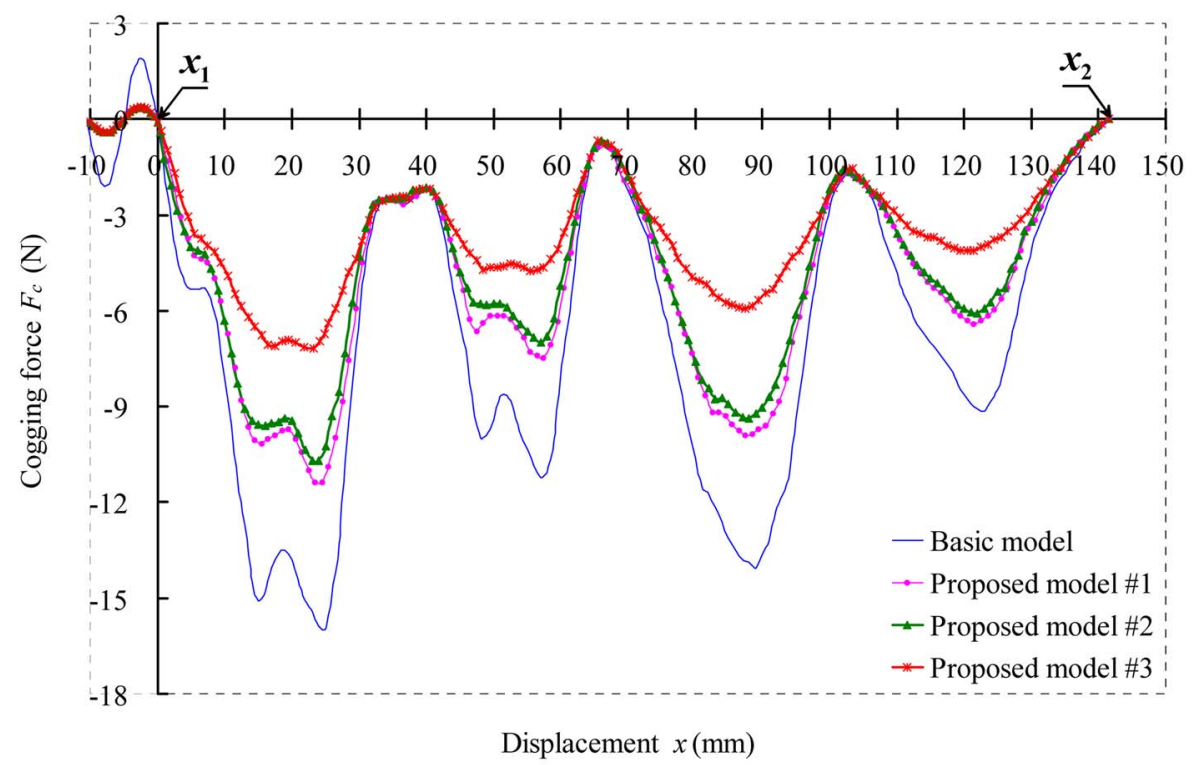

(b)

Fig. 5. (Color online) Cogging force (4 poles, 17 Slots): (a) All regions, (b) Superimposed waveforms of the cogging force of each model that are generated at the ejection interval, $x_{1}$ is the position immediately before the mover passes the exit end of the armature $(\mathrm{mm})$, and $x_{2}$ is the position of the mover after it has completely passed the exit end of the armature (mm).

made in both the basic model and proposed model with a 3-D numerical analysis by the FEM. As indicated by Fig. 5(a), we discovered that when we deform the shape of the outlet edge at the armature, the cogging force of each model is changed. In Fig. 5(a), it was difficult to compare the value of the cogging force in each model, at this point, so we superimposed the cogging force waveform generated at each model by calculating the distance from the point where the mover begins to move beyond the armature area $\left(x_{1}\right)$ to the point where the mover passes completely beyond the armature area $\left(x_{2}\right)$, to compare the cogging force in ejection interval of the each model. In other words, we made point " $b$ " of the basic model the reference point, and aligned the points " $\mathrm{d}$ " of the cogging force waveforms at the ejection interval of the proposed model with point " $b$ " of the basic model, and calculated 


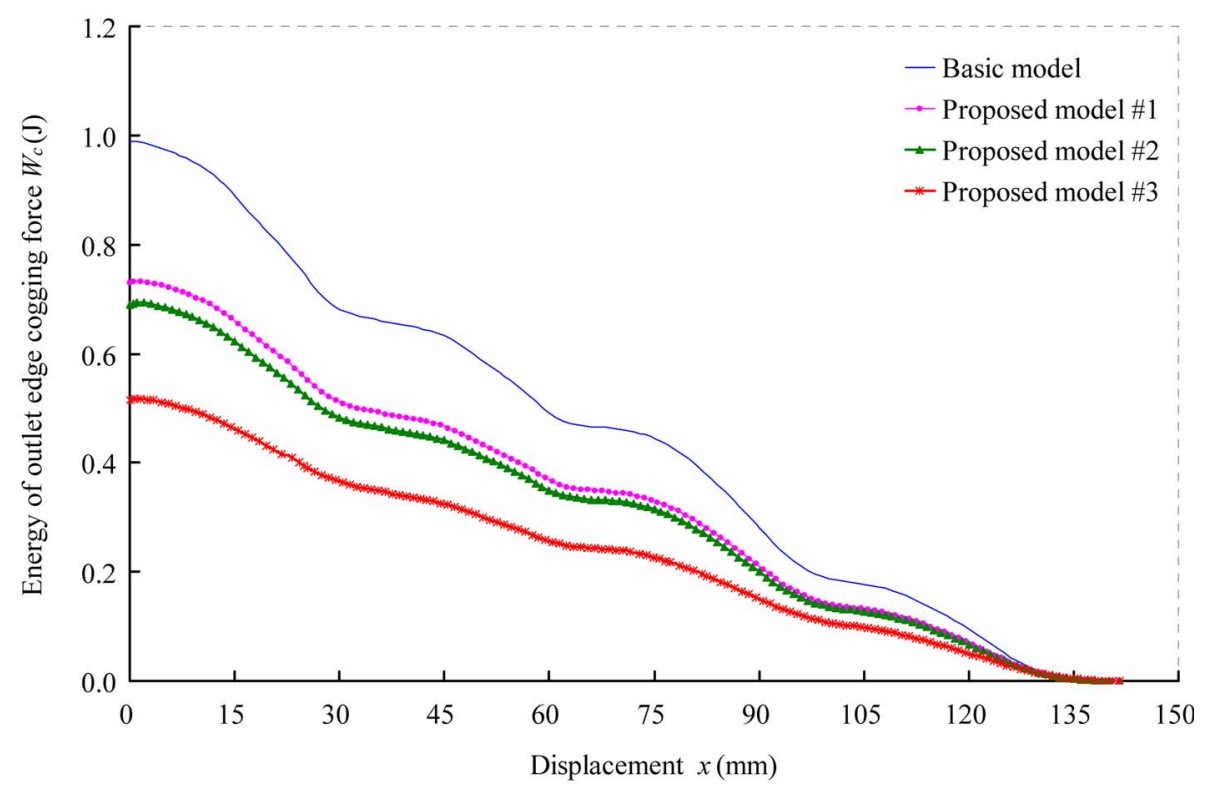

Fig. 6. (Color online) Energy of the outlet edge cogging force at the ejection interval.

the distance at the ejection interval. Superimposed waveforms of the cogging force of each model that are generated at the ejection interval are shown in Fig. 5(b). As indicated by Fig. 5(b), it can be proved that the cogging force from the models which deformed the shape of the outlet edge of the armature at the ejection interval is less than that of the basic model. In the basic model, the maximum cogging force is $16.1 \mathrm{~N}$. However, in proposed model \#3, which decreases the cogging force the most among the proposed models, the maximum cogging force is $6.59 \mathrm{~N}$. Moreover, when we compared two proposed models (\#1, \#3), we found that the cogging force of proposed model \#3, which had an armature width one-third the original width, decreased more than the model that had an armature width two-thirds the original width. Although we can see the difference in the outlet edge cogging force in Fig. 5, because it was difficult to judge the relative merits of each one, evaluation was performed using the energy conversion method in order to evaluate the outlet edge cogging force generated at the ejection interval. Based on the results of Fig. 5, we calculated the energy of the outlet edge cogging force generated at the ejection interval. This energy is calculated as follows;

$$
W_{c}=\int_{x_{1}}^{x_{2}} F_{c}(x) d x
$$

where $F_{c}(x)$ is outlet edge cogging force at the ejection interval $[\mathrm{N}], x_{1}$ is the position immediately before the mover passes the exit end of the armature [mm], and $x_{2}$ is the position of the mover after it has completely passed the exit end of the armature $[\mathrm{mm}]$.
Fig. 6 shows the energy of the outlet edge cogging force at the ejection interval. A position of $0 \mathrm{~mm}$ is the point at which the mover begins to move beyond the armature area, and a position of $142 \mathrm{~mm}$ is the point at which the mover passes completely beyond the armature area. From the results of Fig. 6, we discover that the outlet edge cogging force energy at the ejection interval has a maximum of $0.99 \mathrm{~J}$ in the basic model and a maximum of $0.51 \mathrm{~J}$ in proposed model \#3. Also, we found that the outlet edge cogging force energy at the ejection interval could be reduced more when using the model with an armature width one-third the original width than when using the model with an armature width two-thirds the original width. Moreover, compared with the basic model, a $47.9 \%$ reduction of the outlet edge cogging force energy is possible when using proposed model \#3. Consequently, we think that, in order to reduce the outlet edge cogging force, it is desirable to reduce the width of the armature by more than one-third.

\section{Conclusion}

This paper presents the effect of the outlet edge on the mover's drive, which exists as a result of the discontinuous arrangement of the armature side. Moreover, 3 proposed models with adjusted the widths of the armature of each tooth and apply skew on the permanent magnet by displacing the two magnet segments of each pole have been proposed in order to reduce the cogging force of each outlet edge which affects the driving characteristics.

From the results of a 3-D numerical analysis with a 
FEM, we discovered that the maximum cogging force of the outlet edge of proposed model \#3 was decreased by $9.51 \mathrm{~N}$ compared with the basic model. Moreover, as a result of using the energy conversion method to evaluate the outlet edge cogging force and calculating the energy possessed by outlet edge cogging force, we found that a $47.9 \%$ reduction of the outlet edge cogging force energy was possible using proposed model \#3.

\section{References}

[1] M. Lee, M. Lee, S. Lee, and D. Gweon, J. Magnetics 6, 101 (2001).
[2] D. Son, J. Magnetics 8, 93 (2003).

[3] R. Akmese and J. F. Eastham, IEEE Trans. Magn. 28, 3042 (1992).

[4] M. Sanada, S. Morimoto, and Y. Takeda, IEEE Trans. Industry Appl. 33, 966 (1997).

[5] J. Chang, J. Kim, D. Kang, and D. Bang, J. Magnetics 15, 64 (2010).

[6] Y. Kim and S. Jung, J. Magnetics 14, 47 (2009).

[7] Y. Kim, H. Dohmeki, and D. Ebihara, IET Electric Power Appl. 153, 585 (2006). 